\title{
Some Aspects of the Communicating Branch between the Musculocutaneous and Median Nerves in Man*
}

\author{
By \\ Sōtarō IWAMOTO, Kunihiko KIMURA, Yutaka TAKAHASHI \\ and Masayoshi KONISHI \\ Department of Anatomy, National Defense Medical College, \\ Namiki 3-2, Tokorozawa, Saitama 359, Japan \\ - Received for Publication, August 25, 1989-
}

\begin{abstract}
Key Words: Brachial plexus, Communicating branch, Comparative anatomy, Median nerve, Musculocutaneous nerve
Summary: Fascicular arrangement of the human brachial plexus is examined on $\mathbf{2}$ common cases and 3 peculiar cases in which a communicating branch was observed between the median and the musculocutaneous nerve. The musculocutaneous nerve consists of spinal nerves from C.5, 6 and 7 . The branch to the coracobrachialis receives its fibers from $C .7$ before it leaves the musculocutaneous nerve in 3 cases and after it leaves the musculocutaneous nerve in one case. In one case, C.7 does not send a branch to the coracobrachialis. The median nerve arises by two roots, one from the lateral cord, and the other from the medial cord of the brachial plexus. In a case in which a communicating branch was observed from the median nerve to the musculocutaneous, the fibers from C.7 join to the median nerve via the medial cord. Thus the median nerve involved all elements of the spinal nerve from C.5 to T.1. The elements of the median and the musculocutaneous nerves, therefore, are not affected by appearance of the communicating branch. The communicating branch between the median and the musculocutaneous nerves, consists of the fibers arised from C.5 and C.6, in all examined cases.
\end{abstract}

In man, the musculocutaneous nerve arises from the lateral cord of the brachial plexus. Generally, its fibers are derived from C.5, 6 and 7, but the root arised from C.7 is often absent. The branch to the coracobrachialis leaves the musculocutaneous nerve before it enters the muscle. Usually, it receives its fibers from C.7. Occasionary, a independent branch arised from $C .7$ is send to the coracobrachialis. The branches to the biceps and brachialis leave the musculocutaneous nerve after it has pieced the coracobrachialis. It is continued into a forearm as the lateral cutaneous nerve of the forearm. The median nerve arises by two roots, one from the lateral cord and the other from the medial of the brachial plexus.

The median and musculocutaneous nerves present frequently irregularities in their origins from the lateral cord of the plexus. Some of fibers of the median nerve run for some distance in the musculocutaneous nerve before they join their proper trunk; less frequently the reverse is the case. In this condition, some of fibers of the musculocutaneous nerve run with the median. Nevertheless there has been no satisfactory explanation given for its derivation. There are few reports on the fascicular arrangement of the brachial plexus and its branches. The present study reveals fascicular arrangement of the spinal nerve roots and the communicating branch between the musculocutaneous and the median nerves. Embryological and comparative anatomical relations of the anomalous conditions on the musculocutaneous and median nerves in man are discussed.

\section{Materials and Methods}

Brachial plexus was examined in two common cases and three peculiar cases. In peculiar case 1, the musculocutaneous nerve perforated the coracobrachial muscle and sent out a well developed communicating branch to the lateral cord. In cases 2 and 3, the communicating branch was observed from the musculocutaneous nerve to the median and from the median nerve to the musculocutaneous, respectively. Two common cases in which the communicating branch was not observed between both nerves were also examined for control.

In each specimen, after removing fibrous sheaths of the brachial plexus, nerve fibers were collected into a compact bundles to keep the relationship between their

* Dedicated to the Late Professor Tomoo Nakayama (1909-1989).

Address: Dr. Kunihiko Kimura, Department of Anatomy, National Defense Medical College, Namiki 3-2. likorozawa, Saitama, Japan. 
spinal origins and peripheral branches.

\section{Results}

1. Fascicular arrangement in common cases (Plate 1a). The musculocutaneous nerve arised from the lateral cord, consisted of 3 fascicular groups from C.5 and 4 fascicular groups from C.6. The fasciculus arised from C.7 joined to this nerve and distributed to the coracobrachialis. After sending the musculocutaneous nerve, the remaining fibers of the lateral cord was united with elements of the medial cord to form the median nerve.

\section{Fascicular arrangement in peculiar cases}

(1) In case 1, the superior trunk was divided into two groups, one well developed musculocutaneous nerve and the other fairly weakly median nerve elements of the lateral cord (Plate 1b). The musculocutaneous nerve sent out two fasciculus to the lateral cord after it pierced the coracobrachialis. The median nerve received two roots arised from superior trunk, the "median" elements, in the lateral cord. A small part of it was united with the fasciculus arised from C.7 and took an ordinary course. On the other hand, a large number of the "median" elements descended in the trunk of the musculocutaneous nerve till the nerve pieces the coracobrachialis, and joined lateral cord passing through the communicating branch. The coracobrachialis received two muscular branches, one from the musculocutaneous nerve and the other from C.7 independently. The latter, the deep branch (Koizumi, 1989), distributed a proximal deep part of this muscle (Fig. 1).

(2) In case 2 (Plate 1c), the musculocutaneous nerve sent out the communicating branch to the median nerve, but large part of the "median" elements of the superior trunk united with the fasciculus arised from

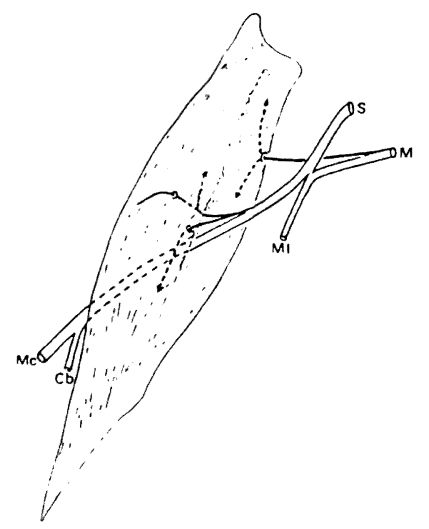

Fig. 1. Nerve supply to the coracobrachial muscle in case 1. $\mathrm{Cb}$; communicating branch to the median nerve, $M$; middle trunk, $\mathrm{Mc}$; musculocutaneous nerve, $\mathrm{Ml}$; lateral root of the median nerve, $S$; superior trunk
C.7 and took an ordinary course observed in common cases. We had failed to clear the peripheral distributions of each fiber, but found that the median and musculocutaneous nerves were similar to that of the common cases in its fiber constitutions. In this case the communicating branch was consisted of a part of the fibers in the superior trunk arised C.5 and C.6.

(3) In case 3, the median nerve sent out the communicating branch to the musculocutaneous nerve (Plate 1d). Its fascicular arrangement of the brachial plexus was completely different from other cases. The superior trunk was consisted of the fasciculi arised from C. 4,5 and 6 . The middle trunk joined only the medial cord to form the median nerve. But it did not send a fiber either to the lateral cord nor to the coracobrachialis. The constituent elements of the median nerve in this case were the same as that in other cases.

Fascicular arrangement of the median and the musculocutaneous nerves in case 1 was examined in the upper arm region (Plate 2). The fasciculus of each nerve descended along the upper arm composing a interwoven arrangements, so it was impossible to follow each peripheral branch to its origin at the spinal nerve roots. The communicating branch was composed of two fascicular bundles. The bundles exchanged many communicating fibers with other fasciculi and joined into the mascular branch to the pronator teres and flexor carpi radialis and into the palmar cutaneous branch, respectively.

\section{Discussion}

In this study, the fascicular arrangements of the brachial plexus take various patterns. It seems that existence of the communicating branch between the musculocutaneous and the median nerves gives no influence to the constitutions of fascicular arrangements. It is possible that there are ontogenetical relation between variations of the fascicular arrangement and developmental process of the brachial plexus. Various patterns observed in relation between the median and the musculocutaneous nerves in man, are normally observed in some kinds of animals. Comparative anatomical relationship of the brachial plexus in man and other animals is of great interest.

According to gross anatomical studies (Testut, 1883; Kerr, 1918; Hirasawa, 1931; Ferner, 1938; Monden, 1942; Horiguchi and Yamada, 1985; Kosugi et al., 1989), the incidences of the communicating branches, from the musculocutaneous nerve to the median, from the median to the musculocutaneous and each together, are $15-30 \%, 3-13 \%$ and $0-5 \%$, respectively. No one refers to the characteristics in fascicular arrangement of the communicating branch between the musculocutaneous and median nerves.

In some rare cases in which musculocutaneous nerve fused with median nerve (Elst, 1928; Imokawa, 1975; 
Fujita, 1942; Nakamura et al., 1976; Watanabe et al., 1985; Iwamoto et al., 1989-b), such a variation would be occurred related with phylogenetic development of the coracobrachialis.

Ferner (1938) and Serisawa et al. (1978) suggested that the fusion of the musculocutaneous to the median nerve is related with the appearance of the accessory head of the biceps brachii. However, it is suspiciously that such a anomalous condition of the musculocutaneous nerve described above occurs related with a accessory head of the biceps. Kosugi et al. (1989) observed musculocutaneous nerve on the arms possessing normal biceps muscle and found the communicating branch in 24 out of 110 arms $(21.8 \%)$. This value is similar to it observed in arms involved specimens which had accessory head of the biceps (Testut, 1883; Kerr, 1918; Hirasawa, 1931; Monden, 1942; Horiguchi and Yamada, 1985). Koizumi (1989) examined 10 specimens in which the musculocutaneous nerve fused to the median nerve and found only 2 cases in which a accessory head of the biceps is observed.

According to the embryological studies (Lewis, 1902; Gräfenberg, 1906; Iwata, 1955), the brachial plexus appears as a single radicular cone in the superior limb bud. This cone divides longitudinally into ventral and dorsal segments. The ventral segment gives roots to the median and ulnar rami with the musculocutaneous nerve arising from the median. Adachi (1910)'s C type brachial plexus may indicate a primitive pattern of differentation in the radicular cone. It is possible that some of fibers take an aberrant course such as communicating branch observed in peculiar cases of this study because of failure in differentiation.

Borchardt \& Wjasmenski (1917) analysed fascicular arrangement of the median and musculocutaneous nerve and found that peripheral rami of the communicating branch from the musculocutaneous to the median nerve joined muscular branches to the flexor digitorum superficialis and the palmar cutaneous branch. The ramification of the communicating branch in case 1 of this study showed a similar pattern to their case. From these observations, it seems that the communicating branch has no-specific role in its distribution.

According to Adachi (1910), Miller (1934) and Harris (1939), a similar pattern to Adachi's C type in the brachial plexus is observed in various species of mammals. Usually, the musculocutaneous nerve sends out the communicating branch to the median nerve in dogs (Allam et al., 1952; Hashimoto, 1960; Sisson and Grossman, 1961; Miller et al., 1969; Zietzschmann et al., 1974). The median nerve sends out the branch to the musculocutaneous nerve in macaques (Howell and Straus, 1933; Chase and DeGaris, 1940; Sugiyama, 1960; Urbanowicz, 1964; Ohashi, 1968). In general, an independent musculocutaneous nerve is absent in Artiodactyla and Perissodactyla (Raimers, 1925-a;
Sisson and Grossman, 1961; Arlamowska-Palider, 1970; Zietzschmann et al., 1974). But there are some structural differences in the brachial plexus between these animals and man. In dogs, C. 5 does not take part in the formation of the brachial plexus, and the junction between the superior and the inferior cords, socalled the axillary loop, is absent. From this facts, Reimers (1925-b) thought that the communicating branch forms a lateral part of the median nerve.

Based on the study of facsicular arrangement of the brachial plexus in the macaque, Iwamoto et al. (1989-a) stated that the communicating branch from the median to the musculocutaneous nerve, consists of fibers arised from C.7 and that both superior and middle trunks do not interchange their fibers in the lateral cord except the mascular branch to the caracobrachialis arised from C.7. Thus in the macaques, the superior trunk does not send a fiber to the median nerve, so the muscular branch to the pronator teres are consisted of only fibers arised from C.7. According to Clemente (1985), in man, the musculocutaneous nerve may give a branch to the pronator teres.

In spite of their morphological similarity of the brachial plexus, it seems that the variation of the brachial plexus or the communicating branch in man is essentially differ from other animals.

Such a case observed in case 3 in which the middle trunk does not continue into the lateral cord but into the medial cord occurs less than 4\% (Hirasawa, 1931; Kawasaki, 1940; Obara, 1958; Arakawa, 1960). Well developed roots arised from C.4, 5, 6, in case 3 of this study may indicate that this case belongs to the prefixed type so-called by Harris (1904).

There is no evidence to demonstrate the specific relationship between the communicating branch and fascicular arrangement of the brachial plexus.

\section{References}

1) Adachi, B.: Beiträge zur anatomie der Japaner. XII. Die Statistik der Muskelvarietäten. Z. Morph. Anthorop., 12: 261-312, 1910.

2) Allan, M. W., Lee, D. G.. Nulsen, F. E. and Fortune, E. A.: The anatomy the brachial plexus of the dog. Anat. Rec., 114: 173-179, 1952.

3) Arakawa, H.: Zum Plevus brachialis der Japaner. Mie Medical Jounal, 3: 107-148, 1952.

4) Arlamowska-Palider, A.: Comparative anatomical studies of nervus musclocutaneus in mammals. Acta Theriol., XV, 22: 343-356, 1970.

5) Borchardt, M. and Wjasmenski: Der Nervus medianus. Bruns Beitr. zur Krin. Chir., 107: 553-582, 1917.

6) Chase, R. E.\& Degaris, C. F.: The brachial plexus in Macaca rhesus. Am. J. Physical Anthrop., 27: 223-254, 1940.

7) Clemente, C. D.: Gray's Anatomy. (30th ed.) p.1213, Lea \& Febiger, Philadelphia, 1985.

8) Elst, L.: Anomalies musculaires portant sur la loge antérieure du bras. Ann. Anat. Pathol., 5/3: 336-338, 192s

9) Ferner, H.: Der nervus musculocutaneus, seine 
Verlaufsvarietäten am Oberarm und deren Bezeihung zur Entwicklung eines Caput tertium musculi bicipitis. Zeitschr. Anat. Entwick., 108: 567-586, 1938.

10) Fujita T.: Complete fusion of the musculocutaneous and median nerves in a human arm, with remarks on its combination with some anomalies of the biceps brachii muscle. Acta Anat. Nippon., 32: 257-261, 1942. (in Japanese)

11) Gräfenberg, E.: Die Entwicklung der Knochen, Muskeln und Nerven der Hand und der für die Bewegungen der Hand bestimmten Muskeln des unter Arm. anat. Hefte, 30: 1-154, 1906.

12) Harris, $W .:$ The true form of the brachial plexus, and its motor distribution. J. Anat. Physiol., 38: 399-422, 1904.

13) Harris, W.: The morphology of the brachial plexus with a note on the pectral muscle and its tendon twist. pp.43-91, Oxford Univ. Press, London, 1939.

14) Hashimoto, S.: Anatomical, histological and experimental studies on the musculocutaneous nerve of the dog. Fukushima Med. J., 10: 793-813, 1960. (in Japanese)

15) Hirasawa, K.: Untersuchungen über das periphere Nervensystem. Hefte 2, Abt, Anat. Inst. Univ. Kyoto, Series A: pp.116-154, 193-246, 1931.

16) Horiguchi, M. and Yamada, T.: A gross anatomical study on the communication between the median and the musculocutaneous nerves in man. Acta Anat. Nippon., 60: 15, 1985. (abstract in Japanese)

17) Howell, A. B. \& Straus, W. L. Jr.: The anatomy of the rhesus monkey. pp.132-133, 314-317, Hafner, New York, 1933.

18) Imokawa, R.: An anomalous case of the plexus brachialis. Hokuetsu Igakkai Zasshi, 50: 852-856, 1935. (in Japanese)

19) Iwamoto, S., Kimura, K., Takahashi, Y. and Konishi, M.: Brachial plexus of the crab-eating monkey. 7. Fiber components of the plexus. Acta Anat. Nippon., 64: 95, 1989-a. (abstract in Japanese)

20) Iwamoto, S., Kimura, K., Takahashi, Y. and Konishi, M.: Some aspects of the communicating branch between the musculocutaneous nerve and the median nerve in human. Acta Anat. Nippon., 64: 300, 1989-b. (abstract in Japanese)

21) Iwata, H.: Studies on the development of the brachial plexus in Japanese embryo. Rep. Dept. Anat. Mie Prefect. Univ. School Med., 13: 129-144, 1960. (in Japanese)

22) Kerr, A. T.: The brachial plexus of nerves in man, the variations in its formation and branches. Am. J. Anat., 23: 285-395, 1918.

23) Kawasaki, Y.: On the plexus brachialis of the Korean. J. Chosen Med. Assoc., 30: 271-304, 1940. (in Japanese)

24) Koizumi, M.: A morphological study on the coracobrachialis muscle. Acta Anat. Nippon., 64: 18-35, 1989. (in Japanese)
25) Kosugi, K., Morita, T., Koda, M. and Yamashita, H.: Branching pattern of musculocutaneous nerve. 1. Case possessing normal biceps brachii. Jikei Med. J., 33: 63-71, 1986.

26) Lewis, W. H.: The development of the arm in man. Am. J. Anat., 1: 145-183, 1902

27) Miller, M. E.: Anatomy of the dog. pp.578-587, Saunders, Philadelphia, 1969.

28) Miller, R. A.: Comparative studies upon the morphology and distribution of the brachial plexus. Am. J. Anat., 54: 143-175, 1934.

29) Monden, M.: The communication between the median and the musculocutaneous nerves. Juzen Med. St., 47: 2045-2055, 1942. (in Japanese)

30) Nakamura, R., Kanno, Y. and Suenaga, G.: The anomaly of the musculocutaneous nerve. Hokkaido J. Med. Sci., 51: 265-266, 1976. (in Japanese)

31) Obara, M.: On the brachial plexus of the Japanese fetus. J. Nippon Med. School, 25: 94-123, 1958. (in Japanese)

32) Ohashi, H.: Study on the plexus brachialis of the crab-eating macaques. J. Kumamoto Med. Soc., 40: 855-880, 1966. (in Japanese)

33) Reimers, H.: Der Plexus brachialis der Haussäugetiere. Eine vergleichende-anatomische Studie. Zschr. Anat. Entw. Gesh., 76: 653-753, 1925-a.

34) Reimers, H.: Innervation vom M.brachialis der Haustiere. Anat. Anz., 59: 289-301, 1925-b.

35) Serisawa, M., Hagura, N. and Eto, M.: On the third head to the biceps brachii muscle and its relation to the lateral cutaneous nerve of the forearm. Dokkyo J. Med. Sci., 5: 303-312, 1978.

36) Sisson, S. and Grossman, J. D.: The anatomy of the domestic animals. (4th edition) pp.835-875, Charles e. Tuttle, London, 1961.

37) Sugiyama, T.: On the plexus brachialis of the Macaca cyclopsis. Acta Med. Nagasaki., 9: 65-88, 1965.

38) Testut, L.: Memoire sur portion brachiale du nerf musculocutane. Internat. Mschr. Anat. Histol., 1: 305-341, 1883.

39) Urbanowicz, Z.: Les nerfs musclo-cutane, median et cubtal et leurs anastomoses reciproques ches le macacus rhesus. Acta Biol. et Med. Soc. Sc. Gedan., 8: 219-244, 1964.

40) Watanabe, M., Takatsuji, K., Sakamoto, N., Morita, Y. and Ito, $H .:$ Two cases of fusion of the musculocutaneous and the median nerves. Acta Anat. Nippon., 60: 1-7, 1985. (in Japanese)

41) Zietzschmann, O., Ackerknecht, E. and Grau, H.: Ellenberger - Baum, Handbuch der vergleichenden Anatomie der Haustiere. pp.903-931, Spring-Verlag, New York, 1974. 


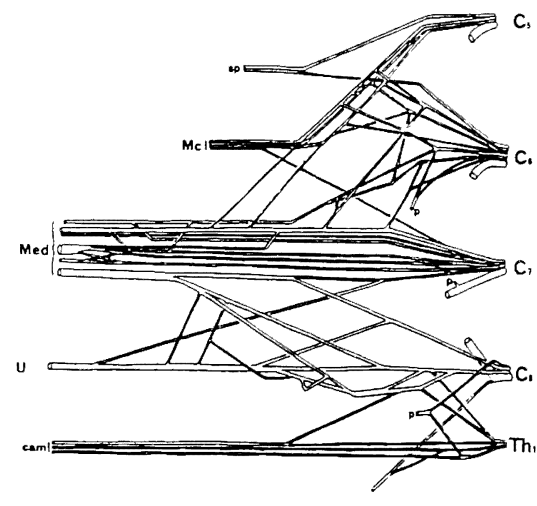

a

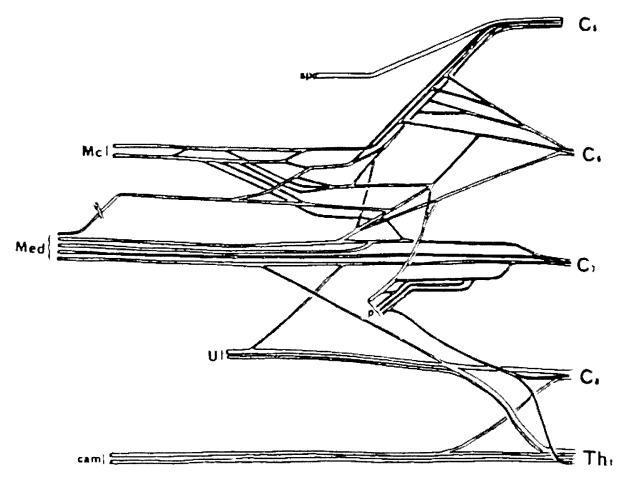

C

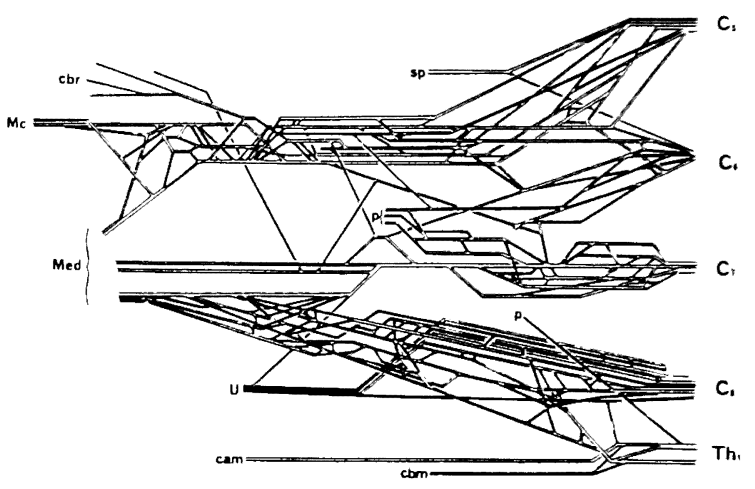

b

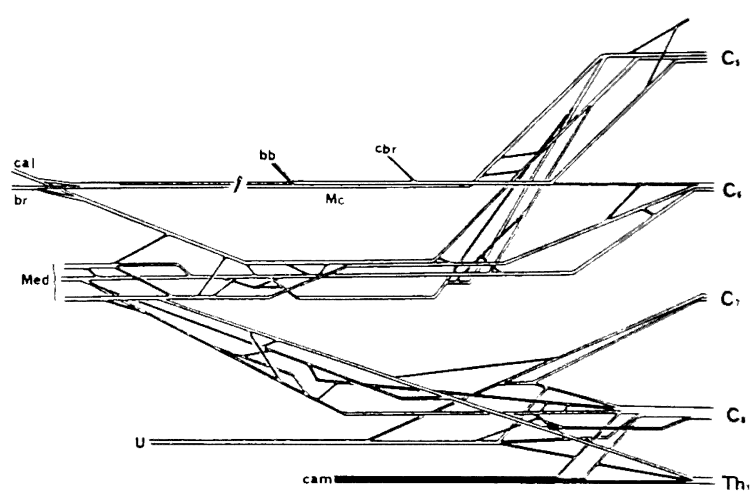

d

\section{Explanation of Figures}

\section{Plate I}

Plate 1. Fascicular arrangements in each specimens.

a; common case. b; case 1. c; case 2. d; case 3. Mc; musculocutaneous nerve, Med; median nerve, U; ulnar nerve, bb; branch to the biceps brachii, br; branch to the brachialis, cal; lateral cutaneous nerve of the forearm, cam; medial cutaneous nerve of the arm, cbm; medial cutaneous nerve of the arm, cbr; branch to the coracobrachialis, p; pectral nerve, sp; suprascapular nerve. 
Plate II

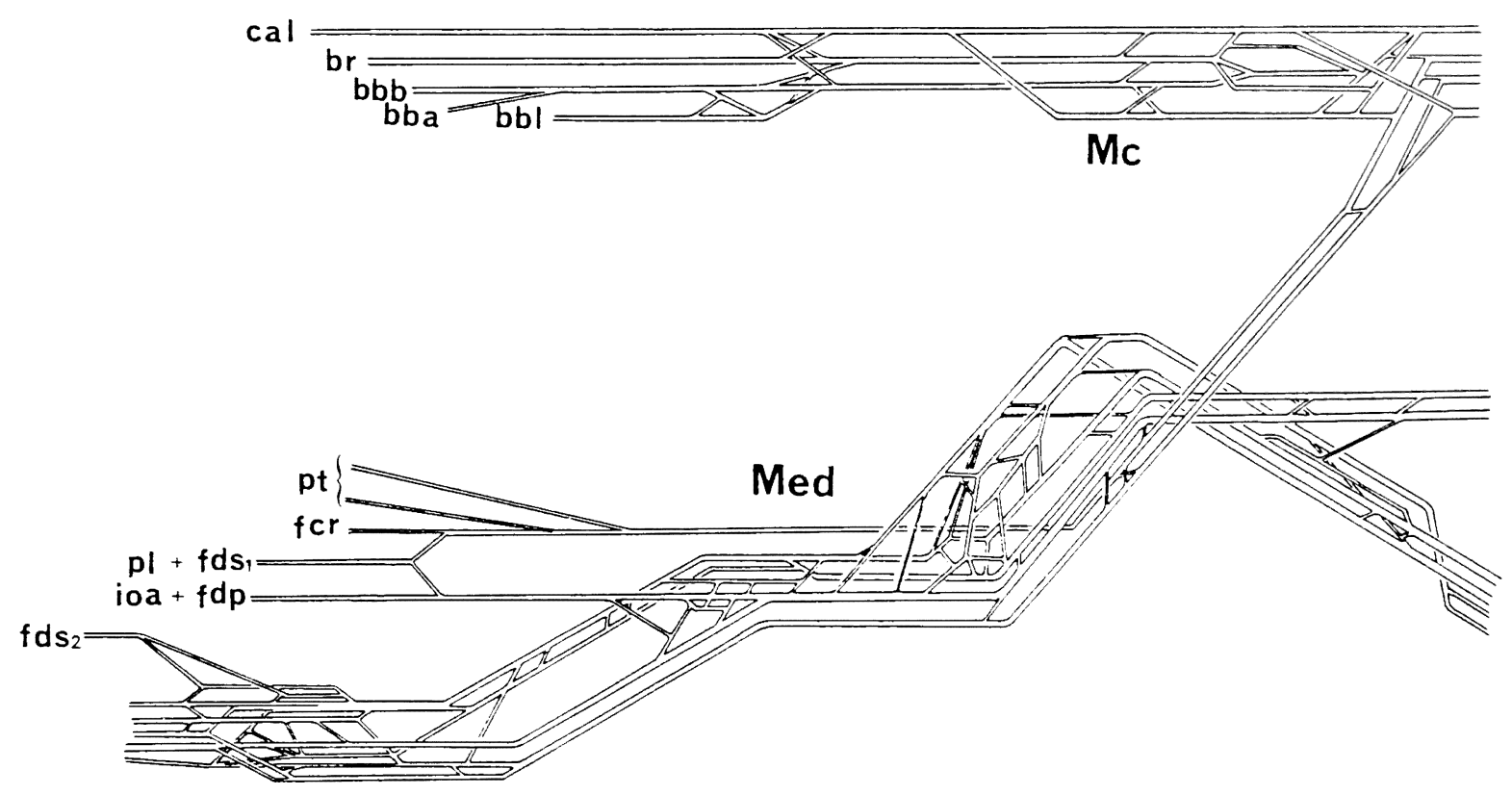

Plate II

Plate 2. Fascicular arrangements of the musculocutaneous and the median nerves in case 1.

Mc; musculocutaneous nerve, Med; median nerve, bba; branch to the accessory head of the biceps, bbb; branch to the short head of the biceps, bbl; branch to the long head of the biceps, br; branch to the brachialis, cal; latral cutaneous nerve of the forearm, $\mathrm{fcr}$; branch to the flexor carpi radialis, fds; branch to the flexor digitorum superficialis, fdp; branch to the flexor digitorum profundus, ioa; anterior interosseous nerve, pl; branch to the palmaris longus, pt; branch to the pronator teres. 